\title{
Effect of Dimple on Aerodynamic Behaviour of Airfoil
}

\author{
Amit Kumar Saraf $^{\# 1}$, Dr. Mahendra Pratap Singh ${ }^{* 2}$, Dr. Tej Singh Chouhan ${ }^{\# 3}$ \\ \#1 Department of Mechanical Engineering, Jagannath University Jaipur, India \\ 1amitsaraf11@rediffmail.com \\ *2 Department of Mechanical Engineering, Jagannath University Jaipur, India \\ ${ }^{2}$ mpsingh_76@yahoo.co.in \\ \#3 Principal, Rajdhani Institute of Engineering Technology Jaipur India \\ ${ }^{3}$ tejsingh7@gmail.com
}

\begin{abstract}
In order to boost the efficiency of an airfoil, surface of the airfoil is altered. A two dimensional airfoil was analysed with and without dimples on the upper surface using CFD software. NACA0012 non cambered airfoil with and without dimples were used for analysis with k- $\varepsilon$ turbulent model. Both were compared keeping in mind the coefficients of lift and drag. Dimples were located at four different positions and compared mutually with smooth airfoil. The velocity of flow was keeping constant for different angles of attack. In CFD analysis results were fluctuated with size of grid so as to get rid of the fluctuating, a grid independency test was done before final analysis. During grid independence test numbers of nodes were increased until constant results come.
\end{abstract}

Keywords: Airfoil, Dimple, Smooth, Lift and Drag

\section{INTRODUCTION}

It is in the nature of human that he always tries to move toward the best performance with less input. He also has various dreams, among those one dream was to take off in the sky freely. Not only flying but flying with speed at a high altitude but there were many difficulties in flying in the sky. To fly at high altitude there is a requirement of lift force. To complete his dream he has been researched for long and succeeded. They did researches in many areas like engine design, aerodynamic shape, quality of fuel, shape of airfoil etc., still there are scopes to improve the performance of airfoil. This study tries to prove the improvement in performance of the airfoil.

In this work surface of the airfoil was modified and compared with smooth airfoil. It was noticed that a golf ball engraved with dimples performs better than without dimples. Pressure drag does not play a central role in aerodynamic bodies than bluff bodies but at a high angle of attack it works. Flow separation starts at high angle of attack and forms wake. In previous studies vortex generators were used to improve the efficiency. Vortex generator's work is to create vortices and hence turbulence in flow. This turbulence is helpful in increasing the time of flow separation.

\section{LITERATURE REVIEW}

(Rao \& Sampath, 2014) Surface modification was done to improve performance of airfoil. Here NACA4412 airfoil was modified with dimple and cylinders. Dimples of two sizes at different location were simulated. Dimples near trailing edge gave good result. Five different experiments were performed with various sizes of dimples and cylinders. But it was noticed that dimples on airfoil showed better result in terms of efficiency of the airfoil.

(A.Dhiliban, et al., 2013) Turbulent in rear side leads to pressure drag. In this smooth airfoil was compared with rough airfoil. Roughness was created on both upper and lower surface towards the trailing edge. For the simulation, velocity of the air was kept constant $(100 \mathrm{~m} / \mathrm{s})$ with $\mathrm{k}-\varepsilon$ std turbulent model. Overall performance of the airfoil was increased on modification towards the trailing edge of the airfoil. Both upper and lower surface modification increases the efficiency, also increased the stall angle.

(Faruqui, Albari, Md.Emrn, \& Ferdaus, 2013) Efficiency of the airfoil can be increased by many ways i.e. flow control method or adaptive technology. Here the author used flow control method. Naca 4315 airfoil was used on CFD tools. Two different models were tested, one was smooth airfoil and other was with bumpy surface on upper side of the airfoil. The bump was generated at $80 \%$ of chord length toward trailing edge. The flow separation starts near 9 degree angle of attack in smooth airfoil. From this it was noticed that there was a drastic change in results of bumpy surfaced airfoil.

(Srivastav, 2012)This study was done on the basis of dimples on the golf ball. This says that drag on golf ball can be reduced by dimples so on this basis author thought that drag could also be reduced if this theory is applied on airfoils. Models were prepared in CATIA V5 R18 and simulated in COMSOL 3.4 and COMSOL 4.29. 
(Juanmian, Feng, \& Can, 2013) Separation bubble and lift coefficient fluctuation with time was observed during study. Laminar separation bubble become unstable and developed primary and secondary vortex. Secondary vortex was much stronger than primary vortex. Analysis was done from $0 \mathrm{o}$ to $10 \mathrm{o}$ angles of attack. As soon as the angle of attack increased, the fluctuation also increased. Laminar separation bubble started moving forwarded for increased angle of attacks and started to reattach to surface of airfoil, hence lift coefficient increased suddenly.

(C.K.Chear \& Dol, 2015) Dimples delay the flow separation for bluff bodies. Author simulated car model with different ratios of dimple using k- $\varepsilon$ turbulent model. Ratio of dimples was taken as depth to diameter.

(Mustak \& Harun, 2017) At zero degree angle of attack, dimples on airfoil do not shows changes in drag compared to smooth airfoil. But at high angles of attack it behaves like bluff body. It leads to delay in separation and wake formation. Also it increases the angle of stall. In this work NACA4415 airfoil was used and drawing was first made in solid works. Hexagonal outward dimpled profile was compared with smooth profile of airfoil. Physical model was prepared with wood and analysed in wind tunnel. Hexagonal surface delays starting of flow separation by 4 degree angle of attack. In case of smooth surface it starts at 120 and for outward dimpled it happens at 16 o angle of attack. Velocity of the air was taken as $43 \mathrm{~m} / \mathrm{s}$.

\section{Turbulent Model}

Turbulent models are used because of limitations of Navier stroke equations. There are many turbulent models used in CFD analysis. Generally k- $\varepsilon$ and k- $\omega$ models are used in fluid flow. Both models are used for streamlined and bluff bodies. Kinetic energy of turbulent fluid flow is solved by $\mathrm{k}-\varepsilon$ turbulent model. This model is less complicated compared to other. Time of computation is also less. This model can be used in low memory computers.

A. $k$ - $\varepsilon$ turbulent models equation

$$
\begin{aligned}
& \frac{\partial}{\partial \mathrm{t}}(\rho \mathrm{k})+\frac{\partial}{\partial \mathrm{x}_{\mathrm{i}}}\left(\rho \mathrm{ku}_{\mathrm{i}}\right)=\frac{\partial}{\partial \mathrm{x}_{\mathrm{j}}}\left[\left(\mu+\frac{\mu_{\mathrm{t}}}{\sigma_{\mathrm{k}}}\right) \frac{\partial \mathrm{k}}{\partial \mathrm{x}_{\mathrm{j}}}\right]+\mathrm{G}_{\mathrm{k}}+\mathrm{G}_{\mathrm{b}}-\rho \epsilon-\mathrm{Y}_{\mathrm{k}}+\mathrm{S}_{\mathrm{k}} \\
& \frac{\partial}{\partial \mathrm{t}}(\rho \epsilon)+\frac{\partial}{\partial \mathrm{x}_{\mathrm{i}}}\left(\rho \epsilon \mathrm{u}_{\mathrm{i}}\right)=\frac{\partial}{\partial \mathrm{x}_{\mathrm{j}}}\left[\left(\mu+\frac{\mu_{\mathrm{t}}}{\sigma_{\epsilon}}\right) \frac{\partial \epsilon}{\partial \mathrm{x}_{\mathrm{j}}}\right]+\mathrm{C}_{1 \epsilon} \frac{\epsilon}{\mathrm{k}}\left(\mathrm{G}_{\mathrm{k}}+\mathrm{C}_{3 \epsilon} \mathrm{G}_{\mathrm{b}}\right)-\mathrm{C}_{2 \epsilon} \rho \frac{\epsilon^{2}}{\mathrm{k}}+\mathrm{S}_{\epsilon}
\end{aligned}
$$

\section{IV.GRID INDEPENDENCE TEST}

(Muralidhar \& Sundrarajan, 2008) The Grid distribution scheme has many limitations. Global error cannot be controlled. But we can control the local errors. For controlling this author increased the no of nodes until he got constant result.

As we increase the number of nodes, result varies with respect to it. But there comes a stage where the results become fixed. This fixed result shows that this is our required number of nodes on which we have to do work as shown in fig. 1 . In this work 102180 numbers of nodes have been used.

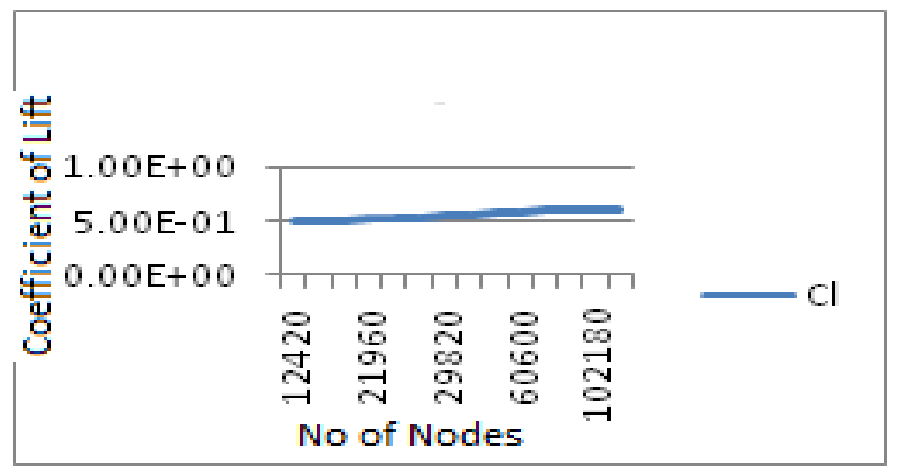

Fig.1 Grid Independence Test

\section{Computation Method}

NACA0012 airfoil smooth profile and dimpled airfoil were used to study the aerodynamic behaviour of the airfoils. The shapes of the airfoil models is shown in fig. 2 and the farfiled and meshing is shown in fig.3, is used for computation in CFD software. Diameter of dimple was taken as $0.02 \%$ of chord.

(airfoiltools.com, 2016) Practical data were taken from this reference. These data were validated to check the accuracy of the work.

(Confluence, 2015) Coordinates of airfoil NACA0012 was downloaded from this source. 
Smooth airfoil's computed results were compared with practical data. This ensured us that we have followed right way for calculation. After that dimples on the airfoil at different location were created. Dimples location affects the results. In this work five dimpled airfoil were used, one is smooth and remaining each have dimples at $10 \%, 25 \%, 50 \%$ and $75 \%$ of chord length. Results of smooth airfoil were compared to outcomes of these five dimpled airfoil. Flow of air was taken $7.3 \mathrm{~m} / \mathrm{s}$ and density was $1.225 \mathrm{~kg} / \mathrm{m} 3$.

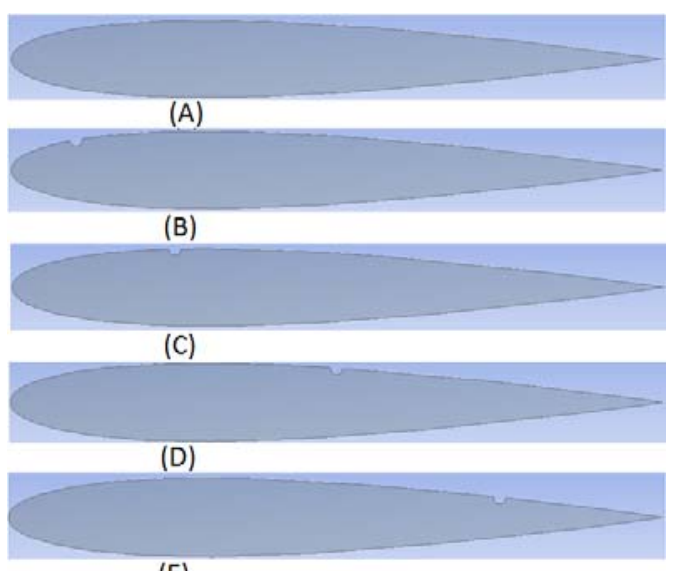

(E)

Fig2. (A)Smooth Airfoil, (B) Dimpled at 10\% of Chord, (C) Dimpled at $25 \%$ of Chord, (D) Dimpled at $50 \%$ of Chord, (E) Dimpled at $75 \%$ of Chord

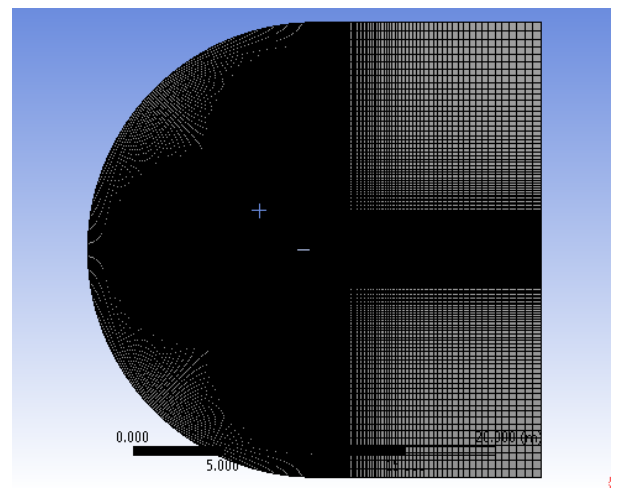

Fig3. Farfield with Mesh

\section{VI.RESULT AND DISCUSSION}

\section{A. 5.1 Pressure Contours}

Fig 4-8 shows pressure contours represents distribution of pressure. At zero degree angle of attack (fig A), upper side and lower side pressure is approximately equal so their lift is minimum. As soon as we increased the angle of attack, result shows that pressure on upper side started decreasing and on lower side it started increasing and stagnation point moved from tip of leading edge to upper surface.

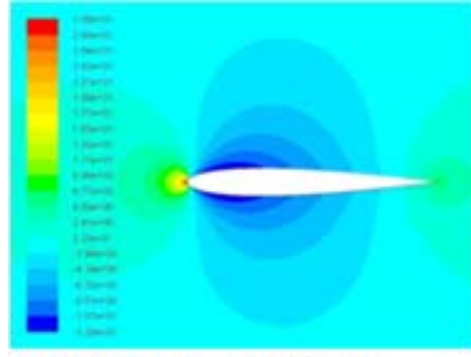

(A) $0^{\circ}$ Angle of Attack

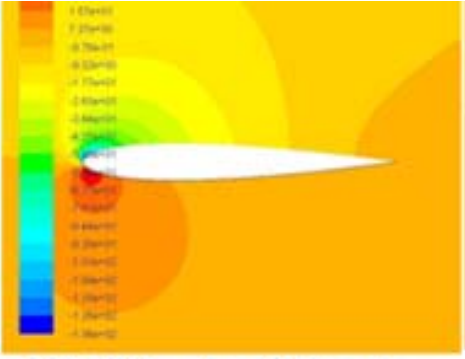

(B) $10^{\circ}$ Angle of Attack

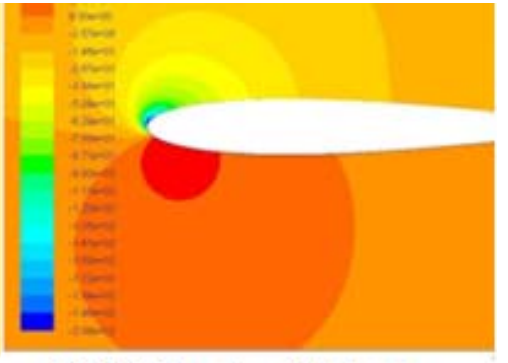

(C) $16^{\circ}$ Angle of Attack

Fig4 Pressure Contours at different angle of attack for Smooth Airfoil 


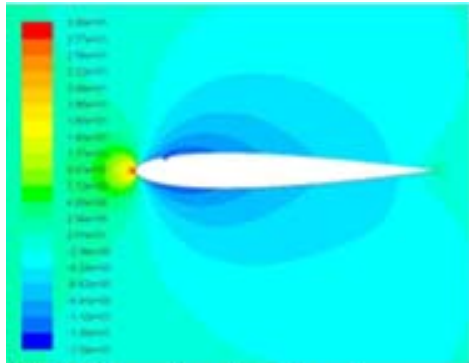

(A) $0^{\circ}$ Angle of Attack

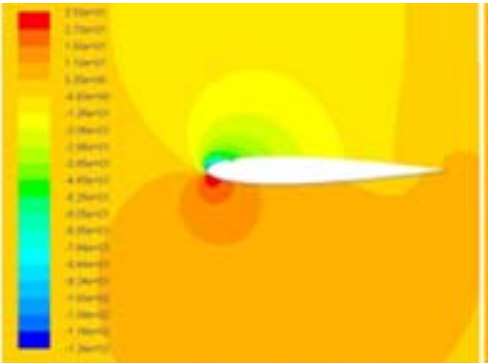

(B) $10^{\circ}$ Angle of Attack

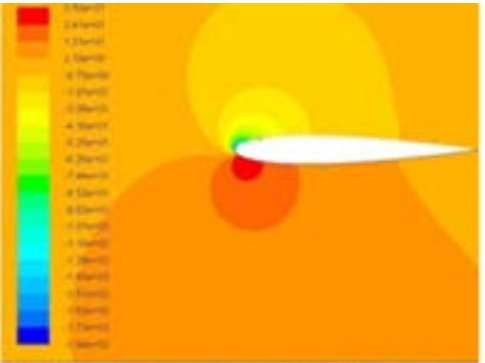

(C) $16^{\circ}$ Angle of Attack

Fig5 Pressure Contours at different angle of attack for Dimpled at 10\% Chord Airfoil

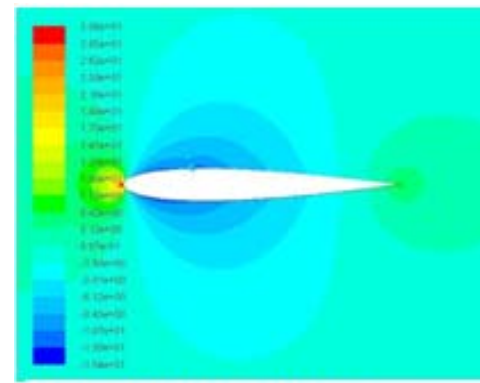

(A) $0^{\circ}$ Angle of Attack

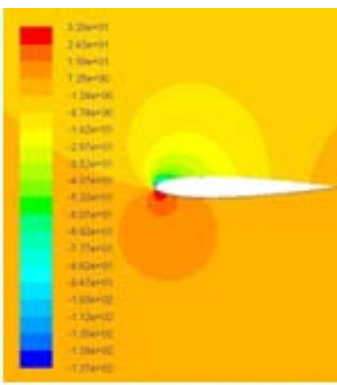

(B) $10^{\circ}$ Angle of Attack

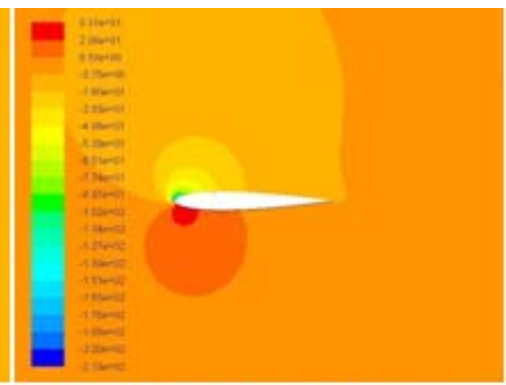

(C) $16^{\circ}$ Angle of Attack

Fig6 Pressure Contours at different angle of attack for Dimpled at 25\% Chord Airfoil

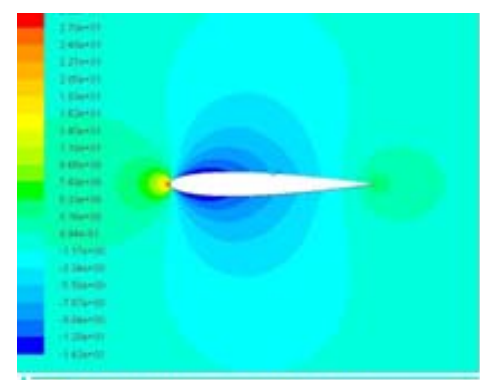

(A) $0^{\circ}$ Angle of Attack

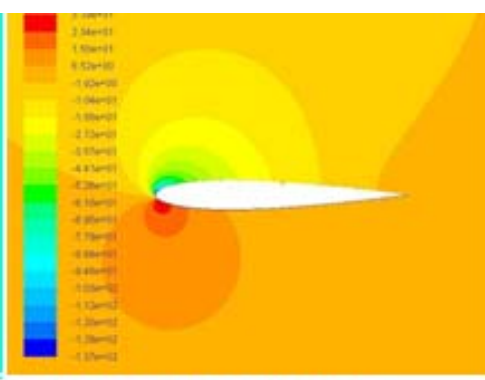

(B) $10^{\circ}$ Angle of Attack

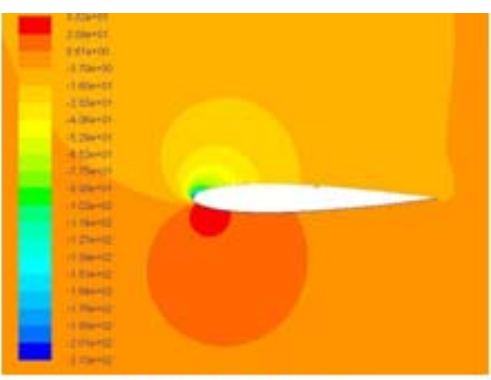

(C) $16^{\circ}$ Angle of Attack

Fig7 Pressure Contours at different angle of attack for Dimpled at 50\% Chord Airfoil

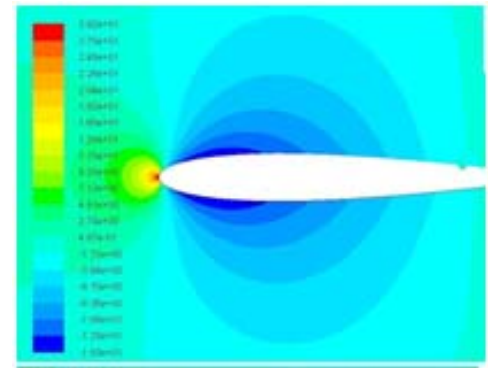

(A) $0^{\circ}$ Angle of Attack

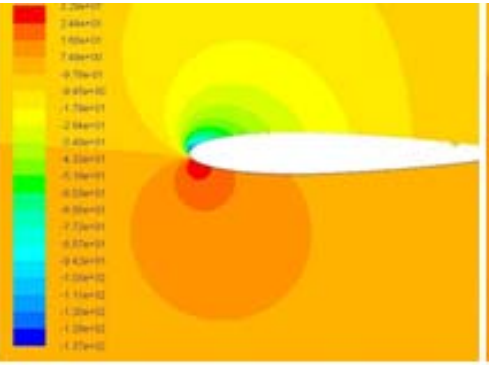

(B) $10^{\circ}$ Angle of Attack

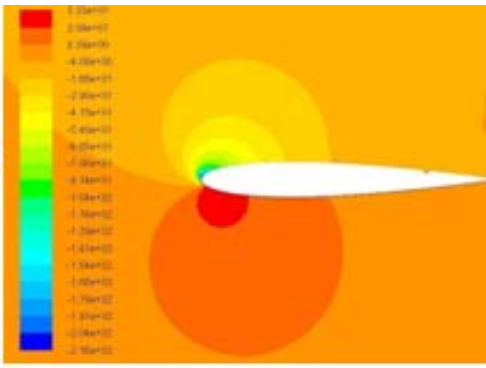

(C) $16^{\circ}$ Angle of Attack

Fig8 Pressure Contours at different angle of attack for Dimpled at 75\% Chord Airfoil

\section{B. Velocity Vectors}

Velocity on upper and lower side of the airfoil is approximately similar at zero degree angle of attack as shown in fig A of 9-13. At 10o angle of attack fluid starts separating and generates wakes. This leads to pressure drag. As we reaches 160 angle of attack separation reaches maximum value, after that lift starts decreasing. 


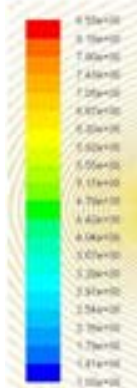

(A) $0^{\circ}$ Angle of Attack

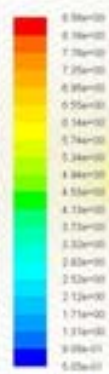

(A) $0^{\circ}$ Angle of Attack

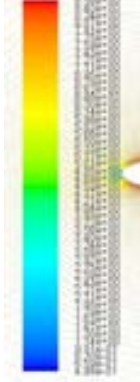

(A) $0^{\circ}$ Angle of Attack

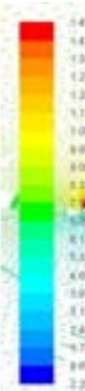

(B) $10^{\circ}$ Angle of Attack

Fig.9 Velocity Vectors for Smooth Airfoil

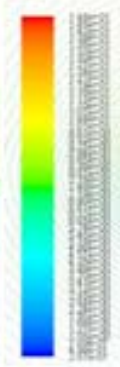

(B) $10^{\circ}$ Angle of Attack

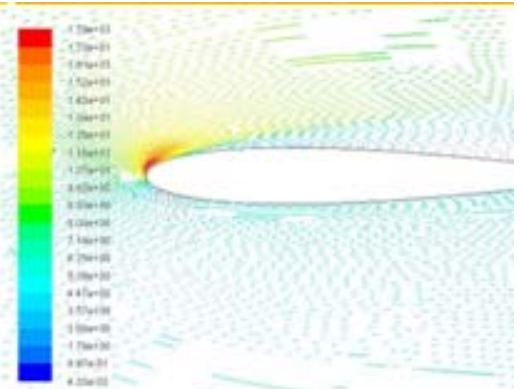

(C) $16^{\circ}$ Angle of Attack

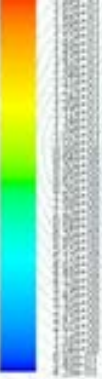

(C) $16^{\circ}$ Angle of Attack

Fig.10 Velocity Vectors of Dimpled at 10\% Chord Airfoil

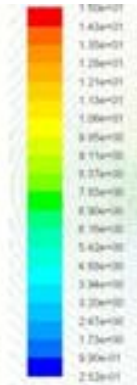

(B) $10^{\circ}$ Angle of Attack

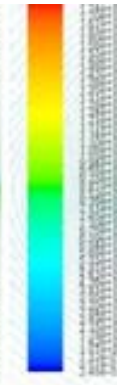

(C) $16^{\circ}$ Angle of Attack

Fig.11 Velocity Vectors of Dimpled at $25 \%$ Chord Airfoil

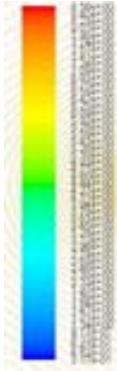

(A) $0^{\circ}$ Angle of Attack

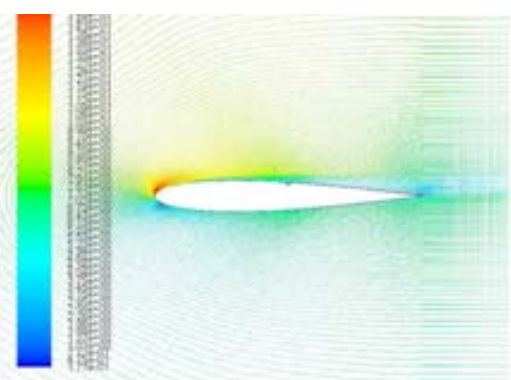

(B) $10^{\circ}$ Angle of Attack

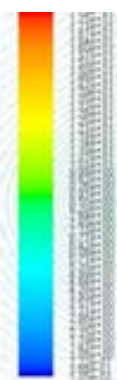

(C) $16^{\circ}$ Angle of Attack

Fig. 12 Velocity Vectors of Dimpled at 50\% Chord Airfoil 


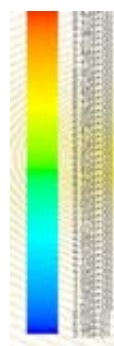

(A) $0^{\circ}$ Angle of Attack

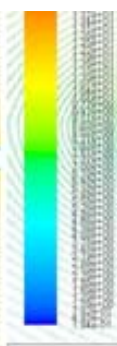

(B) $10^{\circ}$ Angle of Attack

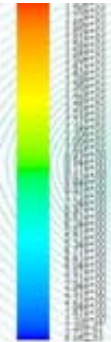

(C) $16^{\circ}$ Angle of Attack

Fig. 13 Velocity Vectors of Dimpled at $75 \%$ Chord Airfoil

\section{Coefficient of Pressure}

Upper curve in fig 14-18 shows the coefficient of static pressure of lower surface and lower curve represents the upper surface of the airfoil. At zero degree angle of attack both curves are identical fig 14-18 (A), this represents that pressure on both surface is approximately similar. At higher angle the difference of pressure near the leading edge is wider, this represents that lift starts from leading edge. It was also proved in contours of pressure diagram.

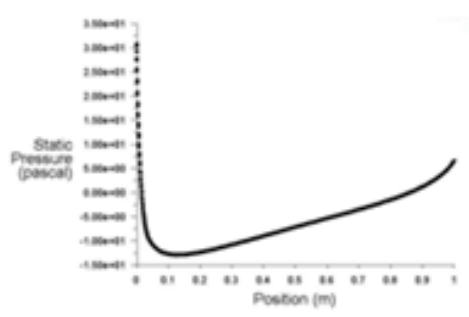

(A) $0^{\circ}$ Angle of Attack

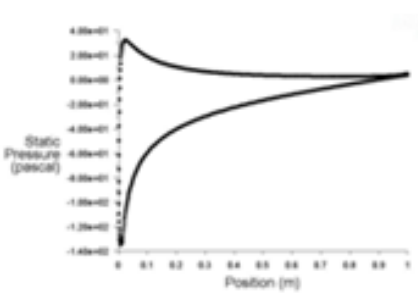

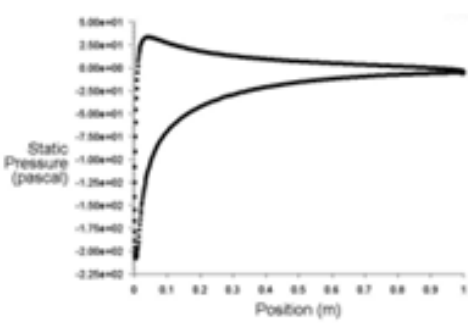

(B) $10^{\circ}$ Angle of Attack

(C) $16^{\circ}$ Angle of Attack

Fig.14 Coefficient of Pressure for Smooth Airfoil

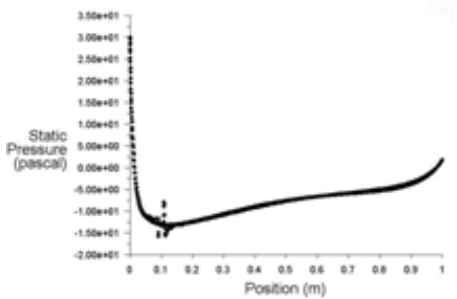

(A) $0^{\circ}$ Angle of Attack

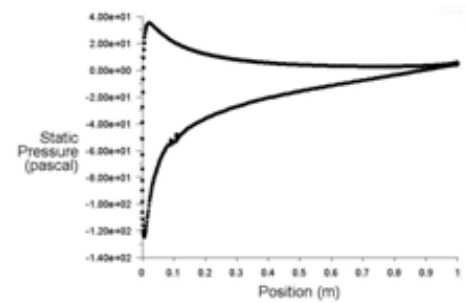

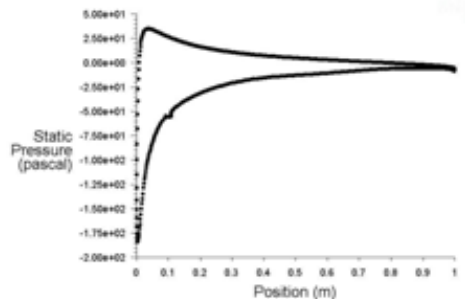

(B) $10^{\circ}$ Angle of Attack

(C) $16^{\circ}$ Angle of Attack

Fig. 15 Coefficient of Pressure of Dimpled at 10\% Chord Airfoil

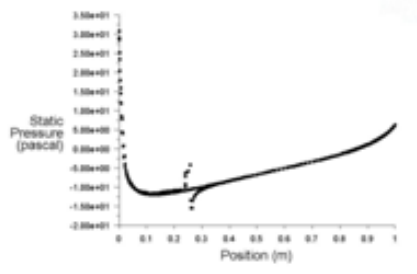

(A) $0^{\circ}$ Angle of Attack

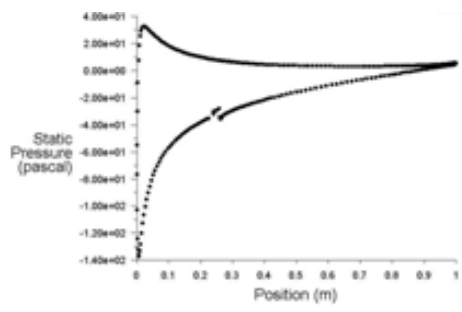

(B) $10^{\circ}$ Angle of Attack

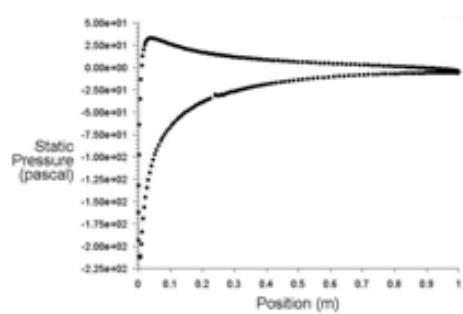

(C) $16^{\circ}$ Angle of Attack

Fig. 16 Coefficient of Pressure of Dimpled at 25\% Chord Airfoil 


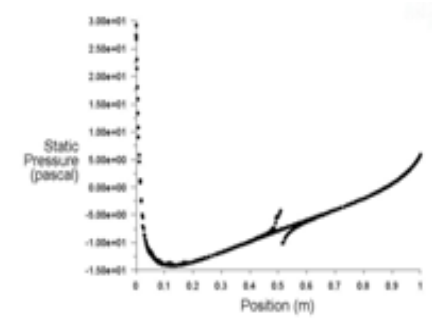

(A) $0^{\circ}$ Angle of Attack
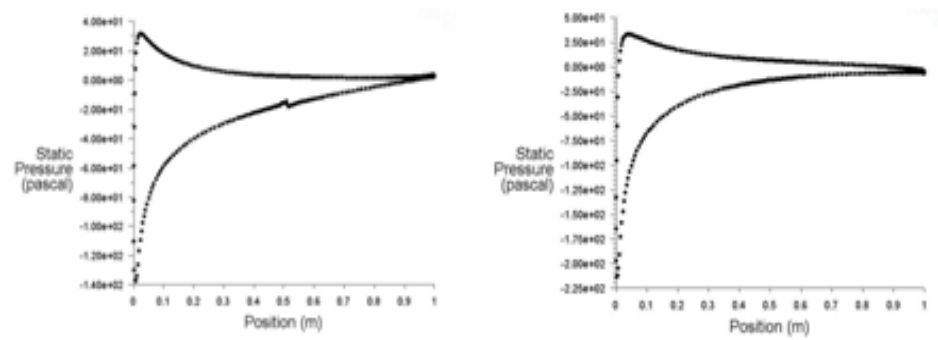

\section{$\begin{array}{ll}\text { (B) } 10^{\circ} \mathrm{Angle} \text { of Attack } & \text { (C) } 16^{\circ} \mathrm{Angle} \text { of Attack }\end{array}$}

Fig. 17 Coefficient of Pressure of Dimpled at 50\% Chord Airfoil

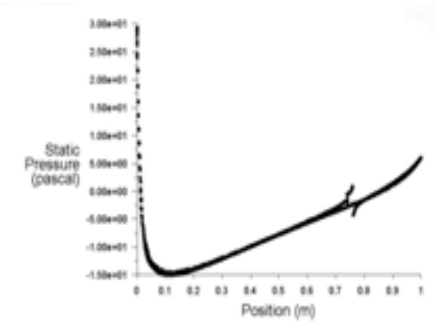

(A) $0^{\circ}$ Angle of Attack
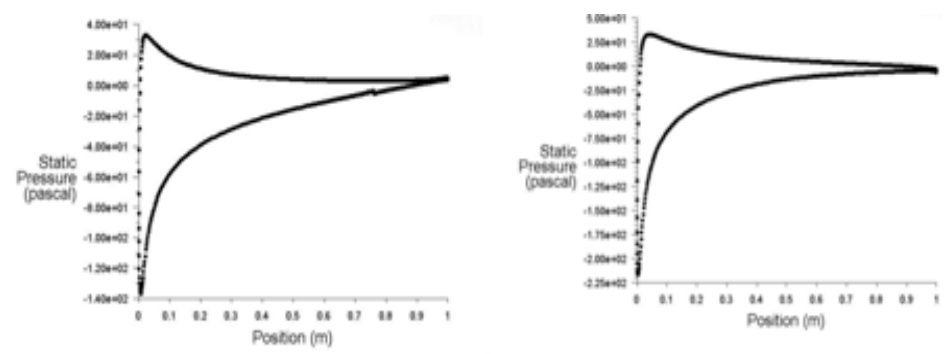

(B) $10^{\circ}$ Angle of Attack

(C) $16^{\circ}$ Angle of Attack

Fig. 18 Coefficient of Pressure of Dimpled at $75 \%$ Chord Airfoil

\section{Streamlines}

Streamlines shows the path of fluid on the airfoil. It was seen from fig 19-23 that at zero degree angle of attack fluid remain stick to the airfoil. At higher anger angle of attack it started separating as shown in fig 19 (B) of the smooth airfoil. Flow separation delayed in the airfoil which is dimpled at $75 \%$ of chord, can be seen in fig 23(B). So it proves that dimpled airfoil performs better than smooth airfoil.

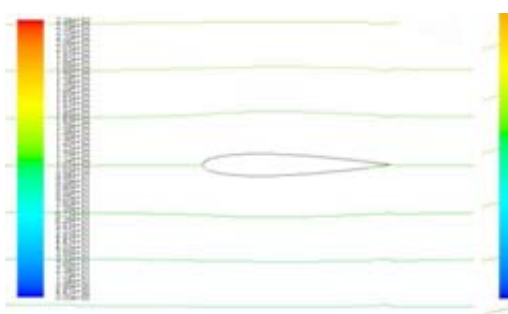

(A) $0^{\circ}$ Angle of Attack

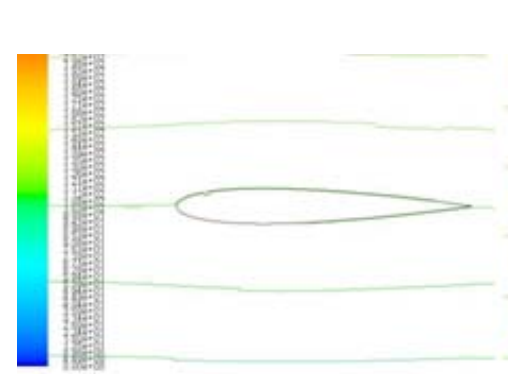

(A) $0^{\circ}$ Angle of Attack
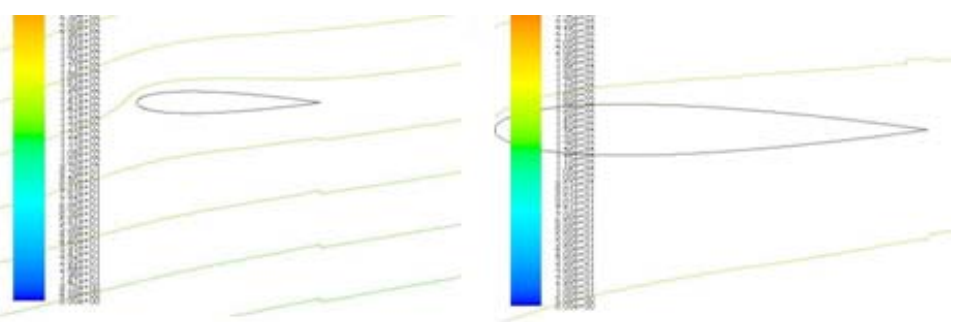

(C) $16^{\circ}$ Angle of Attack

(B) $10^{\circ}$ Angle of Attack

Fig.19 Streamlines for Smooth Airfoil

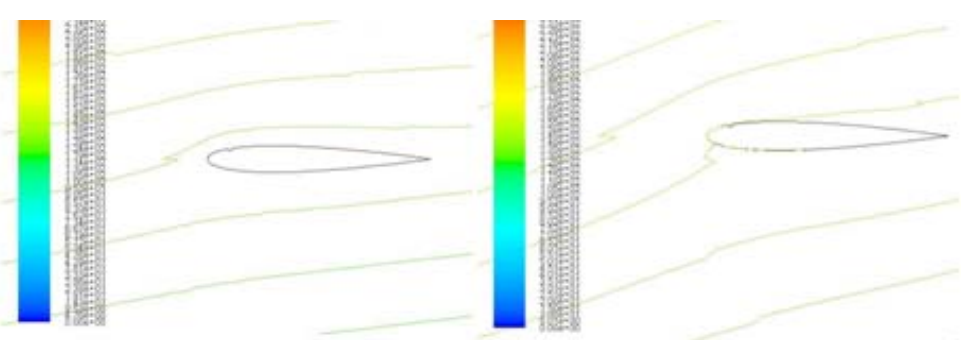

(B) $10^{\circ}$ Angle of Attack

(C) $16^{\circ}$ Angle of Attack

Fig.20 Streamlines of Dimpled at 10\% Chord Airfoil 


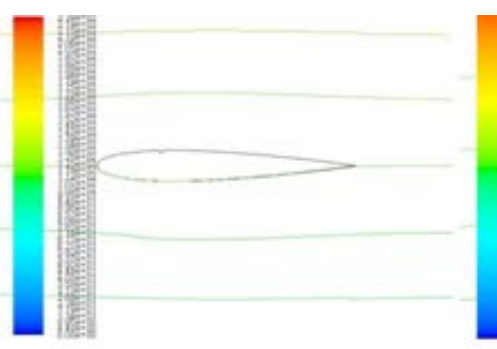

(A) $0^{\circ}$ Angle of Attack

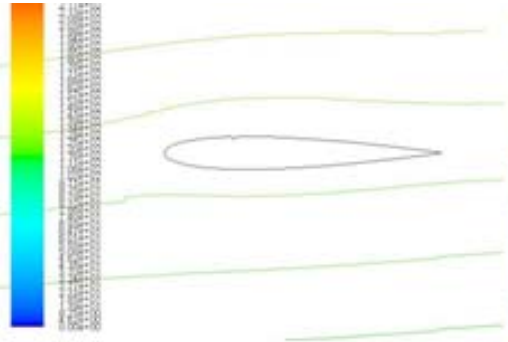

(B) $10^{\circ}$ Angle of Attack
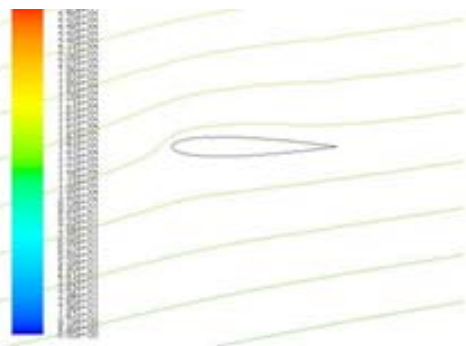

(C) $16^{\circ}$ Angle of Attack

Fig.21 Streamlines of Dimpled at 25\% Chord Airfoil

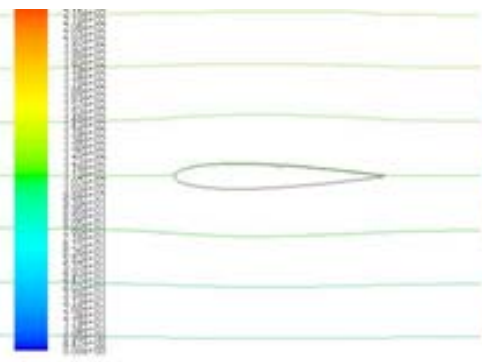

(A) $0^{\circ}$ Angle of Attack

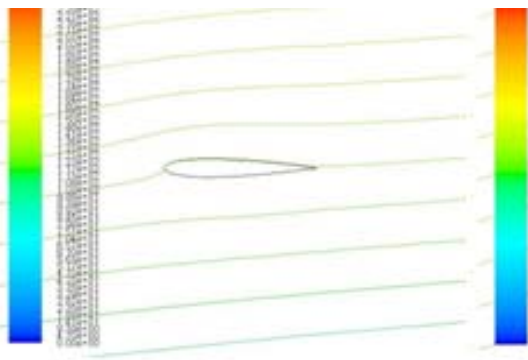

(B) $10^{\circ}$ Angle of Attack

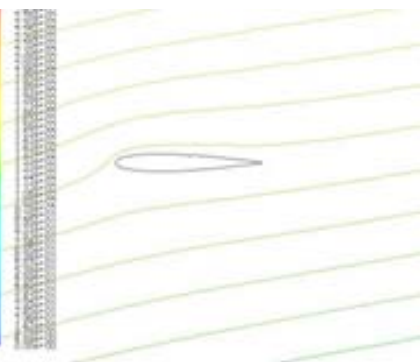

(C) $16^{\circ}$ Angle of Attack

Fig.22 Streamlines of Dimpled at 50\% Chord Airfoil

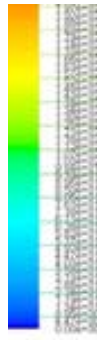

(A) $0^{\circ}$ Angle of Attack

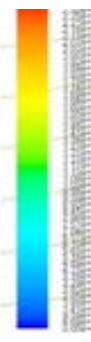

(B) $10^{\circ}$ Angle of Attack

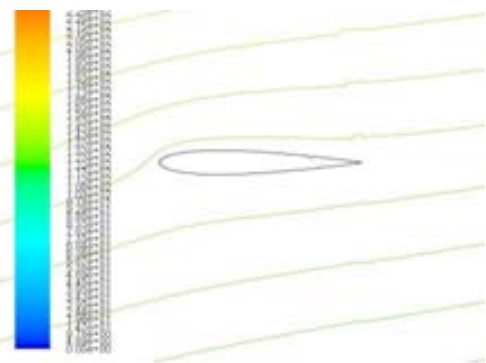

(C) $16^{\circ}$ Angle of Attack

Fig.23 Streamlines of Dimpled at 75\% Chord Airfoil

E. Coefficient of Lift and Drag

CFD analysis was done on 2D NACA0012 Dimpled and Smooth Airfoils. From fig 24 it was seen that dimple at $10 \%$ of chord showed worst result than smooth airfoil. Coefficient of lift was increased and drag was decreased in dimpled airfoil at $75 \%$ of the chord .Dimples at $25 \%$ and $50 \%$ of the chord length also did not performed well.

TABLE I. Variation of Coefficient of lift with Angle of Attack

\begin{tabular}{|l|l|l|l|l|l|}
\hline$\alpha \boldsymbol{\nabla}$ & Cl-Smooth & Cl-10\% & Cl-25\% & Cl-50\% & Cl-75\% \\
\hline 0 & $2.84 \mathrm{E}-05$ & $-1.46 \mathrm{E}-03$ & $-5.98 \mathrm{E}-03$ & $1.50 \mathrm{E}-02$ & $3.50 \mathrm{E}-02$ \\
\hline 2 & $2.13 \mathrm{E}-01$ & $1.61 \mathrm{E}-01$ & $2.02 \mathrm{E}-01$ & $2.28 \mathrm{E}-01$ & $2.48 \mathrm{E}-01$ \\
\hline 4 & $4.21 \mathrm{E}-01$ & $4.17 \mathrm{E}-01$ & $4.05 \mathrm{E}-01$ & $4.36 \mathrm{E}-01$ & $4.56 \mathrm{E}-01$ \\
\hline 6 & $6.21 \mathrm{E}-01$ & $6.19 \mathrm{E}-01$ & $5.97 \mathrm{E}-01$ & $6.36 \mathrm{E}-01$ & $6.56 \mathrm{E}-01$ \\
\hline 8 & $8.12 \mathrm{E}-01$ & $7.78 \mathrm{E}-01$ & $7.79 \mathrm{E}-01$ & $8.27 \mathrm{E}-01$ & $8.47 \mathrm{E}-01$ \\
\hline 10 & $9.79 \mathrm{E}-01$ & $9.36 \mathrm{E}-01$ & $9.44 \mathrm{E}-01$ & $9.94 \mathrm{E}-01$ & $1.01 \mathrm{E}+00$ \\
\hline 12 & $1.12 \mathrm{E}+00$ & $1.04 \mathrm{E}+00$ & $1.10 \mathrm{E}+00$ & $1.13 \mathrm{E}+00$ & $1.17 \mathrm{E}+00$ \\
\hline 14 & $1.20 \mathrm{E}+00$ & $1.04 \mathrm{E}+00$ & $1.17 \mathrm{E}+00$ & $1.21 \mathrm{E}+00$ & $1.29 \mathrm{E}+00$ \\
\hline 16 & $1.19 \mathrm{E}+00$ & $9.62 \mathrm{E}-01$ & $1.11 \mathrm{E}+00$ & $1.20 \mathrm{E}+00$ & $1.29 \mathrm{E}+00$ \\
\hline
\end{tabular}


TABLE II. Variation of Coefficient of Drag with Angle of Attack

\begin{tabular}{|l|l|l|l|l|l|}
\hline$\alpha \downarrow$ & Cd-Smooth & Cd-10\% & Cd-25\% & Cd-50\% & Cd-75\% \\
\hline 0 & $1.43 \mathrm{E}-02$ & $2.41 \mathrm{E}-02$ & $1.80 \mathrm{E}-02$ & $1.34 \mathrm{E}-02$ & $8.24 \mathrm{E}-03$ \\
\hline 2 & $4.92 \mathrm{E}-03$ & $2.66 \mathrm{E}-03$ & $6.83 \mathrm{E}-03$ & $6.81 \mathrm{E}-03$ & $9.20 \mathrm{E}-03$ \\
\hline 4 & $-1.53 \mathrm{E}-02$ & $-1.79 \mathrm{E}-02$ & $-1.30 \mathrm{E}-02$ & $-1.32 \mathrm{E}-02$ & $-1.10 \mathrm{E}-02$ \\
\hline 6 & $-5.06 \mathrm{E}-02$ & $-4.85 \mathrm{E}-02$ & $-4.72 \mathrm{E}-02$ & $-4.52 \mathrm{E}-02$ & $-4.38 \mathrm{E}-02$ \\
\hline 8 & $-9.38 \mathrm{E}-02$ & $-7.18 \mathrm{E}-02$ & $-8.77 \mathrm{E}-02$ & $-8.69 \mathrm{E}-02$ & $-8.88 \mathrm{E}-02$ \\
\hline 10 & $-1.42 \mathrm{E}-01$ & $-1.18 \mathrm{E}-01$ & $-1.35 \mathrm{E}-01$ & $-1.39 \mathrm{E}-01$ & $-1.41 \mathrm{E}-01$ \\
\hline 12 & $-1.94 \mathrm{E}-01$ & $-1.61 \mathrm{E}-01$ & $-1.90 \mathrm{E}-01$ & $-1.91 \mathrm{E}-01$ & $-1.94 \mathrm{E}-01$ \\
\hline 14 & $-2.38 \mathrm{E}-01$ & $-1.89 \mathrm{E}-01$ & $-2.31 \mathrm{E}-01$ & $-2.33 \mathrm{E}-01$ & $-2.41 \mathrm{E}-01$ \\
\hline 16 & $-2.41 \mathrm{E}-01$ & $-1.87 \mathrm{E}-01$ & $-2.32 \mathrm{E}-01$ & $-2.37 \mathrm{E}-01$ & $-2.47 \mathrm{E}-01$ \\
\hline
\end{tabular}

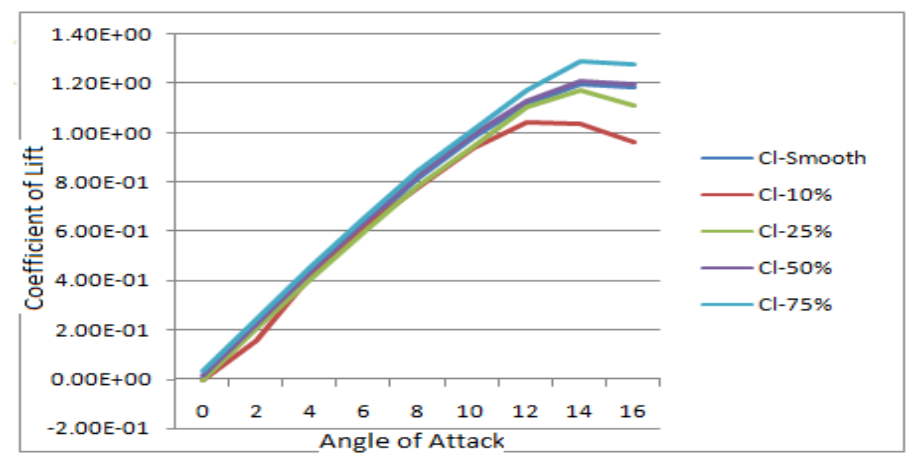

Fig.24Comparision of Lift Coefficient

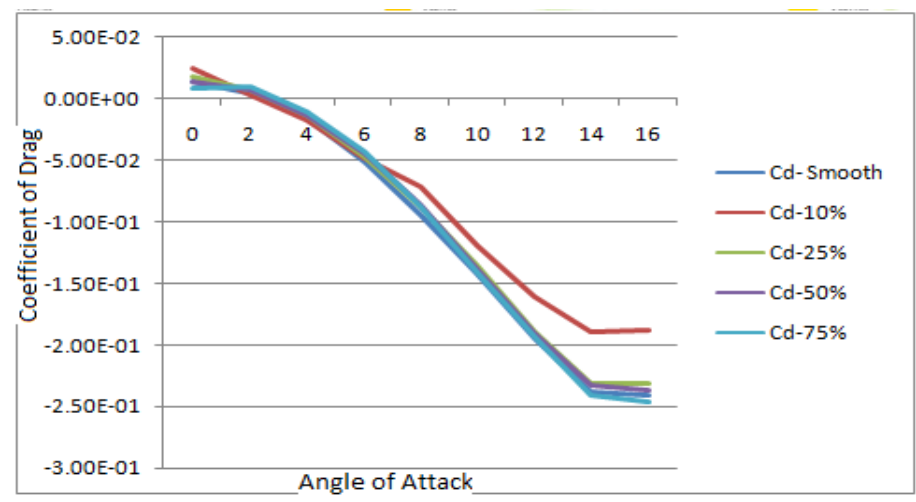

Fig.25Comparision of Drag Coefficient

\section{ConClusion}

Coefficient of lift and drag were analysed and compared at positive angle of attack. Fig 24 shows that coefficient of lift has been increased by $7 \%$ for airfoil having dimple at $75 \%$ of chord length, compared to smooth airfoil. In the same manner it was noticed for coefficient of drag as shown in fig 25 . Coefficient of drag has been reduced by $3 \%$ for the same airfoil. The location of the dimple on the airfoil plays an important role. In this work we noticed that dimple at $75 \%$ of the chord length is the best location for the dimples.

\section{ACKNOWLEDGMENT}

I am using this opportunity to express my gratitude to God, my Parents and everyone who supported me throughout the course of this Research Paper. I am thankful for their aspiring guidance, invaluably constructive criticism and friendly advice during the work. I am sincerely grateful to them for sharing their truthful and illuminating views on a number of issues related to the project.

I express my warm thanks to Dr. M.P.Singh, Jagannath University and Dr. Tej Singh Chouhan for their support and guidance in working in this work.

We would also like to show our gratitude to the Dr. Vivek Sharma, Jagannath University for sharing their pearls of wisdom with us during the course of this research. 


\section{REFERENCE}

[1] A.Dhiliban, P.Meena, Narasimhan, P. S., Vivek, M., Pillai, Nadaraja, S., et al. (2013). Aerodynamic Performance of Rear Roughness Aerofoils. The Eighth Asia-Pacific Conference on wind Engineering (pp. 193-200). Chennai, India: Research Publishing.

[2] airfoiltools.com. (2016, Jan 1). http://airfoiltools.com/polar/details?polar=xf-n0012-il-500000. Retrieved March 2, 2016, from airfoiltools.com: http://airfoiltools.com/polar/details?polar=xf-n0012-il-500000

[3] C.K.Chear, \& Dol, C. K. (2015). Vehicle Aerodynamics:Drag Reduction by Surface Dimples. International Journal of Mechanical, Aerospace, Industrial and Mechatronics Engineering, 9, 202-205.

[4] Confluence, A. (2015, Apr 10). https://confluence.cornell.edu. Retrieved Sep 15, 2015, from https://confluence.cornell.edu: https://confluence.cornell.edu/download/attachments/144976439/naca0012coords.txt?version=1\&modificationDate=1302377518000\& api $=$ v2

[5] Faruqui, S. H., Albari, M., Md.Emrn, \& Ferdaus, A. (2013). Numerical Analysis of the Role of Bumpy Surface to Control The Flow Seperation of an Airfoil. 10th International Conference on Mechanical, ICME 2013 (pp. 255-260). Bangladesh: Elsevier Ltd.

[6] Juanmian, L., Feng, G., \& Can, H. (2013). Numerical Study of Seperation on the Trailing Edge of a Symmetrical Airfoil at aLlow Reynolds Number. Chienese Journal of Aeronautics , 918-925.

[7] Muralidhar, K., \& Sundrarajan, T. (2008). Computation Fluid Flow and Heat Transfer (Second ed.). Kolkata India: Narosa Publishing House PVT LTD.

[8] Mustak, R., \& Harun, M. (2017). Improvement of Aerodynamic Characteristics of an Airfoil by Surface Modification. American Journal of Engineering Research (AJER), 07-14.

[9] Rao, D. P., \& Sampath, S. (2014). CFD Analysis on Airfoil at High Angles of Attack. International Journal of Engineering Research , $3(7), 430-434$.

[10] Srivastav, D. (2012). Flow Control Over Airfoils Using Different Shaped Dimples. 2012 International Conference on Fluid Dynamics and Thermodynamics Technologies (pp. 92-97). Singapore: IACSIT Press.

\section{AUTHOR PROFILE}

Amit Kumar Saraf is persuing PhD from Jagannath University. He has done M.Tech from Rajasthan Technical University in 2013. He has also published many papers and Book..

Dr. Mahendra Pratap Singh having more than 17 years of experience in teaching and industrial field. He has guided many students of Ph D and M.Tech. He was selected for Kirchhoff Research Award-2015 in Mechanical Engineering by IASR. He has also published many books and research papers.

Dr. Tejsingh Chouhan is working as Principal in "Rajdhani Institute of Technology and Management Jaipur". He got first rank during his Mtech. He is having sound knowledge in mechanical softwares. He guided many $\mathrm{PhD}$ and M.Tech Students. 